\title{
Ballistic stretch or aerobic warm-up evoke post- exercise hypotension after maximal exercise
}

\section{Alongamentos balístico ou estático evocam hipotensão pós-exercício depois de exercício máximo}

\author{
Raoni Conceição Dos-Santos ${ }^{1,2}$ \\ César Rafael Marins Costa ${ }^{1,2}$ \\ Wallace Martins Vianna Ribeiro ${ }^{2}$ \\ Iggor Tadeu Bahiense Fernandez ${ }^{2}$ \\ Welington Vilela de Paula² \\ Karolyne Silva Magalhães² \\ Anderson Luiz Bezerra Silveira ${ }^{1,2}$
}

Abstract: Warm-up is broadly used to increase performance and protect against injury in sports. However, the effects of different models of warm-up on maximal exercise and the subsequent recovery period are undetermined. This study aimed to assess the effects of different warm-ups on performance, blood pressure and autonomic control. Methods: 53 subjects rested for 5 minutes and then were randomly allocated to one of four experimental groups: Control (CTR), Aerobic Warm-up (AER), Static (SST) or Ballistic (BST) stretch. Immediately after warm-up, they performed a maximal cycling test and rested for 30 minutes. Heart rate variability (HRV), Systolic (SBP) and diastolic (DBP) blood pressure were assessed throughout the entire experiment. Statistical analysis was performed by one-way ANOVA with Tukey post-test or two-way ANOVA followed by either Bonferroni or Dunnet post-test, when appropriate. Warm-up did not change test performance or HRV ( $p>.05$ ), however, when compared between-groups, SBP was higher in BST against all groups $(\mathrm{p}<.05)$ after warm-up, and lower in SST and AER after maximal test ( $p>05)$. When compared to baseline values SST showed increased SBP in recovery $(\mathrm{p}<.05)$ while only AER and BST showed post-exercise hypotension at 30 minutes ( $\mathrm{p}<.05)$. In conclusion, despite the lack of effects on performance, AER and BST seem to improve while SST seems to impair the recovery of cardiovascular parameters in an autonomic-independent mechanism.

Key words: Blood pressure; Heart rate; Muscle stretching exercises.

Resumo - Aquecimento é comumente utilizado para aumentar o desempenho e proteger contra lesöes no esporte. No entanto, os efeitos de diferentes modalidades de aquecimento sobre o exercicio máximo e subsequente periodo de recuperação não foram determinados. Este estudo objetivou avaliar o efeito de diferentes aquecimentos sobre o desempenho, pressão arterial e controle autonomico. 53 sujeitos descansavam por 5 minutos em seguida eram aleatoriamente alocados em um dos quatro grupos experimentais. Controle (CTR), Aquecimento aeróbio (AER) e alongamentos estático (SST) ou balístico (BST). Imediatamente após o aquecimento eles efetuavam um teste máximo em bicicleta e descansavam por 30 minutos. A variabilidade da frequência cardíaca $(H R V)$, pressão arterial sistólica $(S B P)$ e diastólica $(D B P)$ foram medidas durante todo o experimento. Analise estatística foi feita pelo two-way ANOVA e pós-teste de Bonferroni ou Dunnet quando apropriado. O Aquecimento não alterou a performance ou HRV (p>,05), todavia, quando comparadas entre grupos, SBP aumenta em BST contra todos os grupos após o aquecimento ( $p<, 05)$ e diminui em SST e AER após teste máximo ( $p<, 05)$. Quando comparadas aos valores basais $S S T$ aumenta SBP na recuperação, enquanto apenas AER e BST mostram hipotensão pós-exercício em 30 minutos $(p<, 05)$. Conclui-se que, apesar da falta de efeitos sobre o desempenho, AER e BST parecem melhorar, enquanto SST piora a recuperação de parâmetros cardiovasculares, através de um mecanismo autonômico-independente.

Palavras-chave: Exercício de alongamento muscular; Frequência cardíaca; Pressão arterial.
1 Federal Rural University of Rio de Janeiro. Department of physiological sciences. Rio de Janeiro, RJ. Brazil.

2 Federal Rural University of Rio de Janeiro. Department of physical education and sports. Rio de Janeiro, RJ. Brazil.

Received: 26 February 2017 Accepted: 01 August 2017

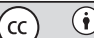




\section{INTRODUCTION}

Warm-up is defined as a "protocol specifically undertaken to prepare for the onset of subsequent physical activity", however the effect of different methods of warm-up are unclear ${ }^{1}$, and coaches often base their warmup sessions on empiric observations rather than scientific studies ${ }^{2}$. The most commonly used warm-ups in sports are composed of low intensity aerobic activity, muscle stretching and sport-specific movements ${ }^{2}$. Muscle stretching is a practice undertaken to increase flexibility which may be performed in several ways, of which the most common are static and ballistic stretching ${ }^{3}$.

Warm-ups aim to increase performance and decrease injury risk by including muscle stretching as a part of this protocol. Warm-ups performed from low to moderate intensities seem to benefit motor tasks ${ }^{4}$, while long or intense warm-ups, which are common in several physical activities, may decrease performance when compared to shorter warm up times ${ }^{5}$. These responses are still controversial in scientific literature and need further elucidations; scientific studies question the indiscriminate use of stretching and, in this regard, muscle stretching may negate the potential beneficial effects of warm-up ${ }^{6}$ by decreasing performance in several conditions, without decreasing risk of injury ${ }^{3}$.

Additionally, few studies have evaluated warm-up separately from muscle stretching ${ }^{2}$. Static stretching reduces strength ${ }^{7-11}$, which raise concerns to its use prior to physical activity. Because of this, ballistic stretching has tended to replace static stretching in modern practices of warm up ${ }^{12}$. Ballistic stretch seems more appropriate to precede physical activity since the reduction in strength is less probable ${ }^{9}$ and performance does not decrease when ballistic stretching is used in conjunction with aerobic warm-up ${ }^{13}$. Previous studies from our laboratory have shown that aerobic warm-up or ballistic stretching have no effect on performance when compared to no warm up ${ }^{14,15}$.

Exercise participates in the control of blood pressure (BP). After exercise, systolic blood pressure decreases below baseline levels and this effect persists for up to 24 hours $^{16}$, an phenomenon deemed post-exercise hypotension $(\mathrm{PEH})^{17}$. Blood pressure disorders are the most common cause of death worldwide; because of this, it is crucial to understand the elements that promote acute changes in blood pressure, as well as their respective mechanisms ${ }^{16}$. Autonomic and non-autonomic factors influence changes in blood pressure during and post-exercise ${ }^{18}$. Studies regarding $\mathrm{PEH}$ often find controversial results, since the characteristics of the exercise protocol and different populations influence the results ${ }^{19}$. So far, no study has assessed if previous warm-up influences $\mathrm{PEH}$ achieved after maximal exercise.

The autonomic nervous system is linked with several physiological systems, among them heart rate. Examining the responsiveness of this system may provide useful information about the functional adaptations 
of the body ${ }^{20}$. When addressing autonomic factors that interfere on blood pressure, heart rate variability (HRV) is the best indirect method to evaluate the autonomic control over the cardiovascular system for humans ${ }^{21}$. Vagalrelated indexes, such as the power density in the high-frequency (HF) range obtained by spectral analysis, are the most widely used variables to examine $\mathrm{HRV}^{22}$. At rest there is a predominance of vagal modulation of the heart, but during exercise sympathetic tone is increased and parasympathetic tone diminishes gradually ${ }^{23}$. After exercise, these autonomic changes are reversed to pre-exercise condition ${ }^{24}$. Rapid vagal recovery may be an important mechanism in preventing excessive cardiac work ${ }^{20}$. However, no study has investigated the warm-up effect on the autonomic modulation or parasympathetic reactivation, immediately after high intensity exercises.

This study compares the effects of warm-up, including ballistic and static stretching, on performance and the recovery of blood pressure and autonomic control after maximal exercise.

\section{METHODOLOGICAL PROCEDURES}

\section{Participants}

Fifty-three men, untrained in cycling or stretching, volunteered to participate in the study. Those that presented high blood pressure $(\mathrm{BP}>130$ / $90 \mathrm{mmHg}$ at rest), osteomiyoarticular injuries, or used medication that impacts the studied variables were excluded from the sample. The number of participants in this study was determined by the software G*Power (Version 3.0.10) in accordance with the experimental delimitation to obtain statistical power (over 0.95) in all analysis.

\section{Study Design}

The institutional research ethics committee approved this study. In the week prior to test protocols, all participants accepted to take part of this research by signing the Informed Consent Form, according to the Resolution 466/2012 of the National Health Council. Afterwards, participants underwent anthropometric measurements and performed a familiarization session identical to the methodological procedures used in the experimental protocols in order to avoid learning influence on the results.

We instructed the participants to refrain from strenuous physical activities, caffeine-based products, smoking, alcoholic beverages, or any substance that interferes in the cardiovascular system at least 48 hours prior to experimental procedure.

The participants (Age: $21 \pm 2$ years old; Weight: $71 \pm 10 \mathrm{~kg}$; Height: $177 \pm 5 \mathrm{~cm}$; Percentage of Fat: $12 \pm 4 \%$ ) were randomly allocated to one of four experimental protocols: Control (CTR) (n=11), Aerobic Warm-up (AER) ( $n=14)$, Ballistic Stretch (BST) $(n=14)$ or Static Stretch (SST) $(n=13)$. In the experiment, all participants rested for 5 minutes, underwent experimental protocols, then performed a maximal cycling test and rested for 30 minutes. Heart rate variability was assessed throughout the entire 
period and blood pressure immediately before, after cycling test, and at 5, 10,20 and 30 minutes of recovery.

\section{Experimental groups}

Due to the recommended duration of warm-up according to Bishop ${ }^{5}$ and the recommended duration of trials for HRV analysis ${ }^{21}$, all protocols were completed within a 5-minute period. CTR rested at the seated position. AER consisted of 5 minutes of cycling in a cycloergometer at a $50 \mathrm{~W}$ load and rhythm between 60 and $80 \mathrm{rpm}$.

The SST group underwent 5 passive stretching exercises in both hemi bodies. The muscles were stretched to the threshold of pain, and held in place for 30 seconds each, achieving a total of 5 minutes. The muscles involved in cycling activity were stretched, the exercises were: (a) Dorsals and Abdominals: Parallel feet, unilateral rotation of trunk; (b) Hamstrings and Gluteus Maximus: With one foot on a support at the hip and knee extended, achieving standing with hands; (c) Hip Adductors: Squat side; (d) Quadriceps: Standing with one of the bent knees, hyperextension of the coxofemoral; (e) Gastrocnemius and Soleus: Unilateral plantar flexion.

The BST group used the same exercises described above for 5 minutes; however, instead of holding the muscle in place the participants did the characteristic bouncing movements of ballistic stretching. In order to ensure the homogeneity of the exercise, the bouncing movements followed the beat of a metronome, set at $60 \mathrm{bpm}$.

\section{Maximal cycling test}

The test consisted of an initial load of $50 \mathrm{~W}$ during 4 minutes, then to $100 \mathrm{~W}$ for 4 more minutes, and then to $150 \mathrm{~W}$ during 4 minutes as well. After that moment the load was increased by $20 \mathrm{~W} / \mathrm{min}$ until exhaustion. The cadence was maintained between 60 and 80 RPM, and exhaustion was defined as inability of the subject to maintain this cadence ${ }^{25}$.

\section{Assessment of autonomic and hemodynamic variables}

Heart rate and its variability were measured by Polar RS800CX [Polar Electro OY, Finland] which was validated in previous studies ${ }^{26}$. The data was analyzed by Kubios HRV software [version 2.1; Biomedical Signaling and Medical Imaging Group, Kuopio, Finland]. The $\mathrm{R}$ waves were assessed under the following parameters: Artifact Correction Level: Strong; Frequency Bands: VLF: 0 - 0.04; LF: 0.04-0.15; HF: 0.15 - 0.4; Interpolation of RR Series: 7Hz; FFT Spectrum: Window Width (s): 512; Window Overlap (\%): 50; Blood pressure was assessed with the automatic Omron BP791IT [Japan].

\section{Statistical analysis}

The analysis of total test time was performed by one-way ANOVA, followed by Tukey's post-test. All other variables were compared with twoway ANOVA, followed by Bonferroni post-test. Additionally, in order to 
recovery of systolic and diastolic blood pressure (SBP and DBP, respectively) the warm-up and cycling test periods were excluded from the analysis and Two-way ANOVA was carried out, with Dunnet post-test against baseline values. Graphpad Prism. v7.0 software was used for all analyses.

\section{RESULTS}

Warm-up did not change total test time (CTR $=1031 \pm 112.7$; AER=995.6 \pm 98.81 ; SST=1023 \pm 137.3 ; and $B S T=1023 \pm 96.33 \mathrm{~s}, \mathrm{p}>0.05$; figure 1). Regarding SBP, when the difference between groups was analyzed, after warm-up BST was higher than all other groups (CTR $=114.4 \pm 7$; $\mathrm{AER}=122.3 \pm 13.26$; SST $=121.9 \pm 13$; $\mathrm{BST}=137.2 \pm 13.3, \mathrm{p}<0.05)$; and af ter maximal test which SST was lower than CTR (CTR=155.7 \pm 12.8 ; $\mathrm{AER}=144.1 \pm 14.2 ; \mathrm{SST}=140.7 \pm 17.9 ; \mathrm{BST}=150.3 \pm 22.8, \mathrm{p}<0.05)$. When the difference in recovery was assessed, SST was higher than baseline at 5 minutes of recovery (baseline $=11.3 \pm 8.3$ vs. $5 \mathrm{~min}=119.4 \pm 12, \mathrm{p}<0.05$ ) and at 30 minutes only AER (baseline $=111.2 \pm 10.6$ vs. $30 \mathrm{~min}=102 \pm 10.4$; $\mathrm{p}<0.05)$ and BST (baseline $=113.4 \pm 7.2$ vs. $30 \mathrm{~min}=106 \pm 6.9$; $\mathrm{p}<0.05)$ were significantly lower than baseline. Additionally, warm-up did not influence diastolic blood pressure in both analysis $(\mathrm{p}>0.05)$.

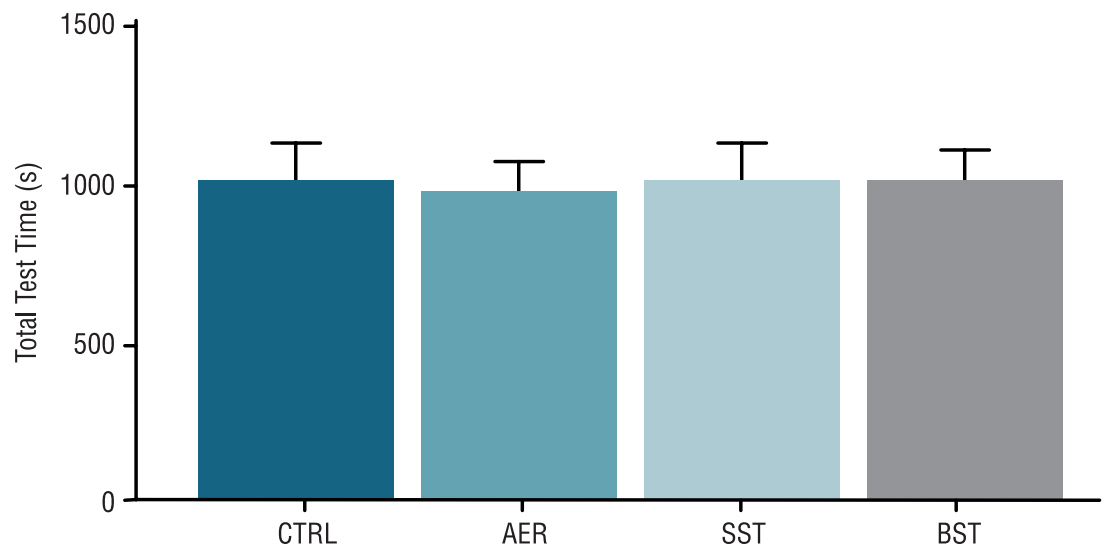

Figure 1. Different pre-exercise activities were not capable of changing performance in a maximal test $(p>.05)$.
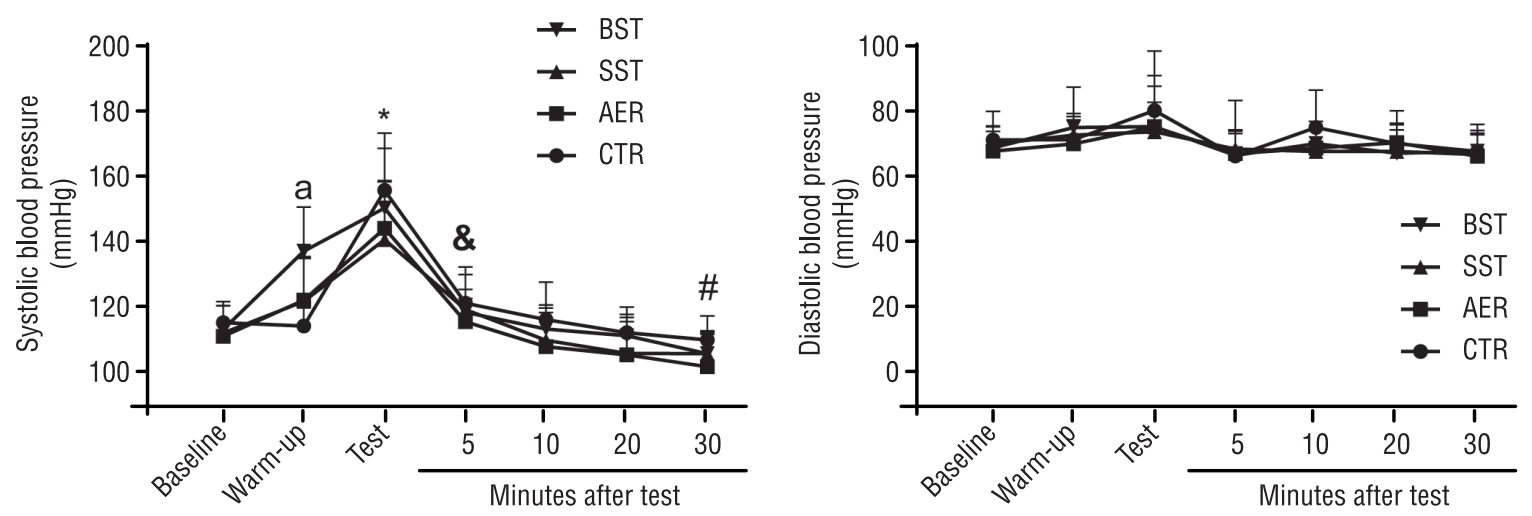

Figure 2. Systolic blood pressure increases after BST when compared to all other groups. After maximal cycling test AER and SST decrease blood pressure lower than CTR. When compared to its starting values, SST is slower in recovering baseline values and only AER and BST achieve post-exercise hypotension at 30 minutes. $a=p<.05$ BST vs all groups; ${ }^{*}=p<.05$ AER and SST vs CTR; $\&=p$ $<.05$ SST vs baseline; \# = $p<.05$ AER and BST vs baseline. 
Autonomic variables (LF, HF, LF/HF) are shown in Table 1. In short, LF and HF showed differences between BST and CTR during warmup $(\mathrm{p}<0.05)$, with no additional differences, and LF/HF ratio showed no differences $(p>0.05)$.

Table 1. Heart Rate Variability Analysis.

\begin{tabular}{lllllllll}
\hline \multicolumn{1}{c}{} & & Baseline & Warm-up & Test & 5 & 10 & 20 & 30 \\
\hline LF (n.u.) & CTR & $61.4 \pm 22.1$ & $65.3 \pm 17.2$ & $66.8 \pm 13.4$ & $71.3 \pm 19.3$ & $81.2 \pm 14.5$ & $74.2 \pm 24.5$ & $78.4 \pm 13.0$ \\
& AER & $64.5 \pm 12.6$ & $73.7 \pm 12.9$ & $75.5 \pm 11.1$ & $81.7 \pm 7.1$ & $78.4 \pm 13.8$ & $83.6 \pm 10.0$ & $82.4 \pm 8.6$ \\
& SST & $65.2 \pm 17.1$ & $77.0 \pm 10.9$ & $74.5 \pm 10.7$ & $80.4 \pm 8.9$ & $82.0 \pm 10.1$ & $82.4 \pm 9.3$ & $84.5 \pm 7.0$ \\
& BST & $58.2 \pm 20.7$ & $77.0 \pm 12.5^{\star}$ & $76.4 \pm 11.0$ & $72.2 \pm 19.0$ & $79.8 \pm 6.0$ & $82.1 \pm 10.2$ & $78.9 \pm 9.6$ \\
HF (n.u.) & CTR & $38.5 \pm 22.1$ & $34.7 \pm 17.2$ & $32.9 \pm 13.4$ & $28.2 \pm 18.8$ & $18.6 \pm 14.4$ & $18.5 \pm 13.1$ & $21.6 \pm 12.9$ \\
& AER & $35.3 \pm 12.6$ & $26.1 \pm 13.0$ & $24.2 \pm 11.0$ & $18.0 \pm 7.1$ & $21.4 \pm 13.5$ & $16.4 \pm 10.0$ & $17.6 \pm 8.6$ \\
& SST & $34.7 \pm 17.1$ & $22.9 \pm 10.9$ & $25.4 \pm 10.7$ & $19.4 \pm 8.9$ & $17.9 \pm 10.1$ & $17.5 \pm 9.3$ & $15.5 \pm 7.0$ \\
& BST & $41.7 \pm 20.7$ & $22.8 \pm 12.4^{*}$ & $23.5 \pm 11,0$ & $24.0 \pm 12.1$ & $20.1 \pm 6.0$ & $17.8 \pm 10.3$ & $21.0 \pm 9.6$ \\
\hline \multirow{2}{*}{ LF/HF } & CTR & $3.2 \pm 4.2$ & $3.3 \pm 4.1$ & $2.7 \pm 1.9$ & $4.3 \pm 3.6$ & $7.8 \pm 6.5$ & $6.3 \pm 5.3$ & $5.7 \pm 5.0$ \\
& AER & $2.0 \pm 0.8$ & $3.5 \pm 2.1$ & $3.6 \pm 1.5$ & $5.0 \pm 2.9$ & $5.6 \pm 4.8$ & $6.3 \pm 2.6$ & $5.7 \pm 3.1$ \\
& SST & $2.4 \pm 1.5$ & $4.2 \pm 2.7$ & $3.4 \pm 2.1$ & $5.2 \pm 3.8$ & $5.9 \pm 3.6$ & $6.2 \pm 5.9$ & $7.5 \pm 6.9$ \\
& BST & $1.9 \pm 1.3$ & $4.7 \pm 2.9$ & $3.9 \pm 1.7$ & $4.2 \pm 2.8$ & $4.4 \pm 1.7$ & $6.8 \pm 4.6$ & $5.6 \pm 5.1$ \\
\hline
\end{tabular}

M - mean; S.D: standard deviation; CTR - Control; AER - Aerobic Warm-up; SST - Static Stretching; BST - Ballistic Stretch; ${ }^{*}-p<$ .05 against $C T R L$.

\section{DISCUSSION}

Warm-up is generally performed previously to exercise to increase performance, however the literature has shown in most studies that warm-up does not change $\mathrm{e}^{1,2}$. We have previously shown that warm-up did not influence performance on different exercise protocols ${ }^{14.15}$. In this study, warm-up was not capable of changing performance in maximal cycling. Indeed, low to moderate intensities of warm-up present mostly neutral effects on performance of several variables, such as strength and power ${ }^{1}$.

However, despite the lack of change on performance, warm-up is able to change blood pressure. Previous studies demonstrated that passive dynamic stretch of the calf muscles increases the activity of the muscular sympathetic afferent and, consequently, increases blood pressure ${ }^{27}$, the effects of whole body ballistic stretch, however, have not been assessed. The present results show that after warm-up, systolic blood pressure is higher only after ballistic stretch, therefore, this warm-up protocol is possibly more intense than aerobic warm-up or static stretching, since it is the only capable of inducing change. Accordingly, ballistic stretching was the only warm-up that changed sympathetic autonomic activity, with increased LF, and decreased HF. This suggests that the increased systolic blood pressure after ballistic stretch is mediated by increased autonomic activity, however this response disappears after maximal test.

After maximal test, systolic blood pressure was lower in the groups 
that performed aerobic warm-up and static stretching when compared to control. This suggests that aerobic warm-ups are capable of blunting increased blood pressure after maximal exercise. The recovery of baseline values of blood pressure in the recovery period was not influenced by aerobic warm-up, however.

In order to assess if warm-up influences post-exercise hypotension, blood pressure was measured during an additional thirty minutes after maximal exercise. Post-exercise hypotension is a phenomenon in which blood pressure decreases below baseline values after exercise ${ }^{17}$. This study demonstrated that after static stretching, systolic blood pressure took longer to return to baseline values, despite being lower after maximal test. Interestingly, the maximal exercise used in this study only achieved post-exercise hypotension when preceded by ballistic stretch or aerobic warm-up. Both control and static stretch groups displayed no difference in post-exercise blood pressure. Indeed, previous studies ${ }^{28}$ demonstrated that static stretching alone was not able to change post-exercise hypotension when followed by intense exercise. Hence, warm-up may be recommended to precede maximal exercise due to its induction of hypotension even when its lack of influence on performance is considered. Ballistic stretching, rather than static stretching, should be used before maximal exercise when $\mathrm{PEH}$ is considered; as has been suggested when other variables, such as strength, were accounted for ${ }^{9,13}$.

Post-exercise hypotension is one the main benefits of exercise in hypertensive populations ${ }^{16}$, therefore, examining the mechanisms underlying this response is crucial. Although the population used in this study consisted of individuals with normal blood pressure, these results indicate that warm-up may alter the hypotensive effect of exercise. However, further studies are necessary to address this issue in hypertensive subjects. Additionally, a maximal exercise was used in this study, the effects of a submaximal exercise on the same parameters would pose an interesting questions for future studies.

Heart rate variability is an indirect method to assess the balance of sympathetic and parasympathetic autonomic control over the heart, with variables such as $\mathrm{HF}$ (which indicate parasympathetic activity) and LF (which indicates sympathetic activity) ${ }^{29}$. Physical exercise influences the autonomic nervous system, with increased sympathetic and decreased parasympathetic modulation during exercise; and after exercise this response returns to normal ${ }^{24}$. Ballistic stretching was the only warm-up that affected autonomic control, with increased LF and decreased HF. This difference disappeared in the maximal test and recovery periods. Therefore, different warm-ups were not capable of changing the response to maximal exercise on autonomic activity. The low intensity warm-ups used in this study might not have been capable of changing the autonomic control of the heart. The responses of the autonomic nervous system are target specific, i.e. a stimulus is capable of changing the activity of sympathetic nerves that project to one region, with no changes in the overall sympathetic activity ${ }^{30}$, therefore 
the direct sympathetic stimulus to the muscle cannot be assessed through HRV analysis and possibly influenced the results.

Blood pressure is set by hormonal, neural, and metabolic control ${ }^{18}$. This study indirectly assessed if neural control is responsible for the effects of warm-up on blood pressure. The lack of differences in $\mathrm{LF} / \mathrm{HF}$ ratio between warm-up protocols indicates that blood pressure effects were independent of autonomic control; thus, hormonal or local regulators of blood pressure might have been at play. Indeed, after exercise, especially high-intensity exercise, plasmatic concentration of several vasoconstrictive hormones, such as angiotensin-II and endothelin-1, contributes to the increases in blood pressure $^{18}$. The effect that different warm-ups achieve on these variables is yet unknown, we hypothesize that warm-up may induce an increased clearance of hypertensive metabolites, that culminates with a systolic blood pressure that drops below baseline levels. However, only aerobic warm-up and ballistic stretching achieved this effect, which indicates that static stretching differently affects local and hormonal mediators of blood pressure, impairing blood pressure recovery. This hypothesis further elucidation, since the plasmatic levels of these hormones were not directly measured in this study. Alternatively, the control of blood pressure after maximal exercise may be due to specific autonomic afferents to the exercised region, rather than an indiscriminate all-or-none autonomic excitation ${ }^{30}$, therefore affecting muscular autonomic activity differently from the heart, which would not be efficiently assessed by HRV.

\section{CONCLUSION}

The results from this study indicate that aerobic warm-up and ballistic stretching, although incapable of changing performance on maximal cycling exercise or parasympathetic reactivation, seems to achieve benefits regarding blood pressure. Conversely, static stretching seems to impair the return of blood pressure to baseline values. The responses on systolic blood pressure are likely mediated by local factors rather than increased autonomic activity. Therefore, regarding acute effects on blood pressure, aerobic warm-up and ballistic stretch are indicated before maximal physical exercise since they decreased blood pressure below baseline levels $30 \mathrm{~min}-$ utes after exercise. The chronic impact of different warm-up practices on blood pressure regulation poses an interesting question for future studies.

\section{Acknowledgements}

The authors would like to formally acknowledge Hanna M Grover for reviewing the text.

\section{REFERENCES}

1. McCrary JM, Ackermann BJ, Halaki M. A systematic review of the effects of upper body warm-up on performance and injury. Br J Sports Med 2015;49(14):935-42. 
2. Fradkin AJ, Zazryn TR, Smoliga JM. Effects of warming-up on physical performance: a systematic review with meta-analysis. J Strength Cond Res 2010;24(1):140-8.

3. Rubini EC, Costa AL, Gomes PS. The effects of stretching on strength performance. Sport Med 2007;37(3):213-24.

4. Bishop D. Warm up II: performance changes following active warm up and how to structure the warm up. Sport Med 2003;33(7):483-98.

5. Tomaras EK, MacIntosh BR. Less is more: standard warm-up causes fatigue and less warm-up permits greater cycling power output. J Appl Physiol 2011;111(1):228-35.

6. Behm DG, Bambury A, Cahill F, Power K. Effect of acute static stretching on force, balance, reaction time, and movement time. Med Sci Sports Exerc 2004;36(8):1397-402.

7. Winchester JB, Nelson AG, Kokkonen J. A single 30-s stretch is sufficient to inhibit maximal voluntary strength. Res Q Exerc Sport 2009;80(2):257-61.

8. Fowles JR, Sale DG, MacDougall JD. Reduced strength after passive stretch of the human plantarflexors. J Appl Physiol 2000;89(3):1179-88.

9. Bacurau RF, Monteiro GA, Ugrinowitsch C, Tricoli V, Cabral LF, Aoki MS. Acute effect of a ballistic and a static stretching exercise bout on flexibility and maximal strength. J Strength Cond Res 2009;23(1):304-8.

10. Avela J, Finni T, Liikavainio T, Niemelä E, Komi P V. Neural and mechanical responses of the triceps surae muscle group after $1 \mathrm{~h}$ of repeated fast passive stretches. J Appl Physiol 2004;96(6):2325-32.

11. Bradley PS, Olsen PD, Portas MD. The effect of static, ballistic, and proprioceptive neuromuscular facilitation stretching on vertical jump performance. J Strength Cond Res 2007;21(1):223-6.

12. Fletcher IM, Monte-Colombo MM. An investigation into the possible physiological mechanisms associated with changes in performance related to acute responses to different preactivity stretch modalities. Appl Physiol Nutr Metab 2010;35(1):27-34.

13. Carvalho FLP, Carvalho MCGA, Simão R, Gomes TM, Costa PB, Neto LB, et al. Acute effects of a warm-up including active, passive, and dynamic stretching on vertical jump performance. J Strength Cond Res 2012;26(9):2447-52.

14. Dos-santos RC, Costa CRM, Di Masi F, Silveira ALB. Acute effects of ballistic stretch and warm-up on sprint on performance and heart rate variability. Col Pesq Ed Fís 2012;11(2).

15. Dos-santos RC, Costa CRM, Di Masi F, Silveira ALB. Effects of Pre-Exercise Activities on Progressive Cycling Test Performance and Autonomic Response. J Exerc Physiol Online 2014;17(5):84-94.

16. Bruneau ML, Johnson BT, Huedo-Medina TB, Larson KA, Ash GI, Pescatello LS. The blood pressure response to acute and chronic aerobic exercise: A metaanalysis of candidate gene association studies. J Sci Med Sport 2016;19(5):424-31.

17. Halliwill JR, Buck TM, Lacewell AN, Romero SA. Postexercise hypotension and sustained postexercise vasodilatation: what happens after we exercise? Exp Physiol 2013;98(1):7-18.

18. Holwerda SW, Restaino RM, Fadel PJ. Adrenergic and non-adrenergic control of active skeletal muscle blood flow: implications for blood pressure regulation during exercise. Auton Neurosci 2015;188:24-31.

19. Brito LC, Queiroz ACC, Forjaz CLM. Influence of population and exercise protocol characteristics on hemodynamic determinants of post-aerobic exercise hypotension. Brazilian J Med Biol Res 2014;47(8):626-36.

20. Borresen J, Lambert MI. Autonomic control of heart rate during and after exercise : measurements and implications for monitoring training status. Sports Med 2008;38(8):633-46.

21. Task Force of The European Society of Cardiology and The North American Society of Pacing and Electrophysiology. Heart rate variability: standards of measurement, physiological interpretation and clinical use. Task Force of the European Society of Cardiology and the North American Society of Pacing and Electrophysiology. Circulation 1996;93(5):1043-65. 
22. Buchheit M, Laursen PB, Ahmaidi S. Parasympathetic reactivation after repeated sprint exercise. Am J Physiol Heart Circ Physiol 2007;293(1):H133-41.

23. Vianna LC, Oliveira RB, Silva BM, Ricardo DR, Araújo CGS. Water intake accelerates post-exercise cardiac vagal reactivation in humans. Eur J Appl Physiol 2008;102(3):283-8.

24. Gladwell VF, Sandercock GR, Birch SL. Cardiac vagal activity following three intensities of exercise in humans. Clin Physiol Funct Imaging 2010;30(1):17-22.

25. de Groot PCE, Thijssen DHJ, Sanchez M, Ellenkamp R, Hopman MTE. Ischemic preconditioning improves maximal performance in humans. Eur J Appl Physiol 2009;108(1):141-6.

26. Nunan D, Donovan G, Jakovljevic DG, Hodges LD, Sandercock GR, Brodie DA. Validity and reliability of short-term heart-rate variability from the Polar S810. Med Sci Sport Exerc 2009;41(1):243-50.

27. Cui J, Blaha C, Moradkhan R, Gray KS, Sinoway LI. Muscle sympathetic nerve activity responses to dynamic passive muscle stretch in humans. J Physiol 2006;576(Pt 2):625-34.

28. Farinatti PT V, Soares PPS, Monteiro WD, Duarte AFA, Castro LAV de. Cardiovascular responses to passive static flexibility exercises are influenced by the stretched muscle mass and the Valsalva maneuver. Clinics 2011;66(3):459-64.

29. Routledge FS, Campbell TS, McFetridge-Durdle JA, Bacon SL. Improvements in heart rate variability with exercise therapy. Can J Cardiol. 2010;26(6):303-12.

30. Gibbins I. Functional organization of autonomic neural pathways. Organogenesis 2013; 27;9(3):169-75.

\section{CORRESPONDING AUTHOR}

Anderson Luiz Bezerra da Silveira Federal Rural University of Rio de Janeiro

Department of Physical Education and Sports

BR-465, km 7, Seropédica, RJ Brazil

Zip code: $23890-000$

Email: andersonsilveira@ufrri.br 